\title{
Lifetime Assessment for Oil-Paper Insulation using Thermal and Electrical Multiple Degradation
}

\author{
Jeongtae Kim ${ }^{\dagger}$, Woobin Kim*, Hung-Sok Park** and Ji-Won Kang**
}

\begin{abstract}
In this paper, in order to investigate the lifetime of oil-paper insulation, specimens were artificially aged with thermal and electrical multiple stresses. Accelerated ageing factors and equivalent operating years for each aging temperatures were derived from results of tensile strengths for the aged paper specimens. Also, the evaluation for the multi-stress aged specimens were carried out through the measurement of impulse breakdown voltage at high temperature of $85^{\circ} \mathrm{C}$. The lifetimes of the oil-paper insulations were calculated with the value of 66.7 for $1.0 \mathrm{~mm}$ thickness specimens and 69.7 for $1.25 \mathrm{~mm}$ thickness specimens throughout the analysis of impulse BD voltages using equivalent operating years, which means that dielectric strengths would not be severely decreased until the mechanical lifetime limit. Therefore, for the lifetime evaluation of the oil-paper insulation, thermal aging would be considered as a dominant factor whereas electrical degradation would be less effective.
\end{abstract}

Keywords: Oil-paper insulation, Degree of polymerization, Tensile strength, Impulse voltage breakdown, Degradation, Lifetime

\section{Introduction}

The insulation degradation in power transformers and OF cables would occur due to thermal and electrical stress in craft papers and insulation oil in the process of decomposition of insulation materials, then dielectric strength would be decreased to lead to failure [1]. However, the correlation between lifetime and multiple-degradation with thermal and electrical stresses is limitedly reported.

Generally, lifetime for oil-paper insulation is considered when the degree of polymerization (DP) of craft paper in insulation decreases to the value of 200 300 from the initial value of $1000 \sim 1200[2,3]$. In other words, if the electric equipment with oil-paper insulation operates at the maximum allowable temperature of $85^{\circ} \mathrm{C}$ continuously for over 30 years, the degree of polymerization of the paper becomes to 300 [4]. But, the measurement of degree of polymerization is costly and not easy. On the contrary, the tensile strength can be easily measured. It is also reported that when tensile strength is lowered to the $50 \%$ of the initial value the degree of polymerization is reduced to approximately 300 [3-5].

Concerned with dielectric property, the inverse power law would be adopted as the electrical degradation with time and the lifetime index is very important to design the insulation layer of the electric equipment. The lifetime index of 25 to 53 at short-time region V-t characteristics

$\dagger$ Corresponding Author: Dept. of Electrical Engineering, Daejin University, Korea. (jtkim@daejin.ac.kr)

* Sanil Electric Co., Ltd institute of technology, Korea. (woobin@sanil.co.kr)

** Power Transmission Laboratory, KEPRI, Korea. (\{hungsok.park, jwkang3985\}@kepco.co.kr)

Received: July 20, 2016; Accepted: October 24, 2016 and 60 to 120 at long-tine region in the transformer insulation models, whereas the lifetime index of 22 at high electric field and 68 at low electric field were reported in OF model cables [4]. However, the studies have been insufficiently reported about impulse breakdown characteristics for thermal or electrical degradation.

In this study, to verify the lifetime of the oil-paper insulation, the specimen were designed and were aged under the thermally and electrically multiple-stresses. Using the measured values of tensile strengths for the aged insulation papers, lifetimes for various temperatures were calculated. Also, the evaluation for thermally and electrically aged model cables was carried out through impulse breakdown characteristics.

\section{Experiments}

\subsection{Specimen}

In general, to study electrical property of insulation paper by use of insulation model, it is not easy to avoid the edge effect which would make an enhanced electric field at the edge of the electrode of the specimen. In this study, to avoid the edge effect, the cable model was adopted with stress relief cones at both sides of the cable model specimen. So, in the middle of the cable model specimen, there must exist butt gaps between paper sheets.

The cable model specimen was designed and prepared as follows;

- Electrode : copper pipe, $400 \mathrm{~mm}$ length, $30 \mathrm{~mm} \varphi$

- Conductor screen : two layers of semi-conductive sheet 
over the electrode, $28 \mathrm{~mm}$ width, $125 \mu \mathrm{m}$ thickness

- Insulation : 8-layer(1 $1 \mathrm{~mm}$ thickness) or 10-layer (1.25 $\mathrm{mm}$ thickness) Craft paper, $28 \mathrm{~mm}$ width, $125 \mu \mathrm{m}$ thickness

- Butt gap(distance between craft paper) : $2 \mathrm{~mm}$

- Stress relief cone : stress cone structure of 50-layer Craft paper, $750 \mathrm{~mm}$ width, $125 \mu \mathrm{m}$ thickness

- Insulation screen : two layers of semi-conductive sheet over the insulation, $28 \mathrm{~mm}$ width, $125 \mu \mathrm{m}$ thickness

- Ground : copper wire winding over the insulation screen

In this study, two types of the insulation layer were prepared such as 8 -layer(1mm thickness) or 10-layer (1.25 $\mathrm{mm}$ thickness) to make different electrical stresses for electrical degradation.

Fig. 1 shows the photo of the cable model specimen used in the experiment and the breakdown occurred at the butt gap of the model cable during the impulse voltage experiment. The moisture in prepared specimens was removed at $120^{\circ} \mathrm{C}$ for 24 hour in an oven, and then the specimens were impregnated in the alkyl-benzene insulation oil for 24 hours at 0.1 torr using vacuum pump.

Before the degradation process, its quality of manufacture for all the prepared specimen was confirmed with 10 -times each positive and negative impulse voltages at the level of the electric field of $750 \mathrm{kV}$ BIL of $154 \mathrm{kV}$ OF cable corresponding to the insulation thickness. Fig. 2 shows the breakdown at the butt gap, which confirms that the

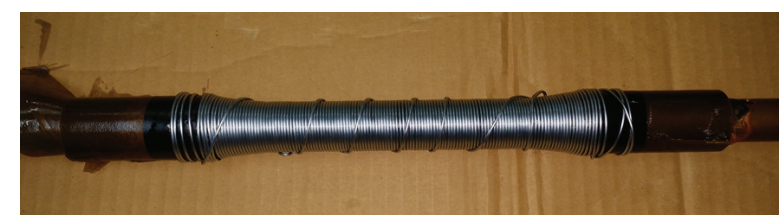

Fig. 1. Prepared cable model specimen

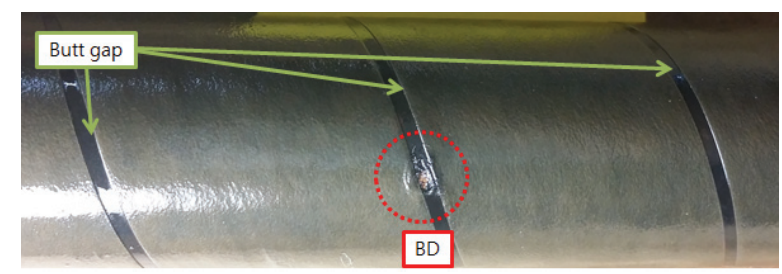

Fig. 2. Impulse voltage breakdown in the butt gap pattern

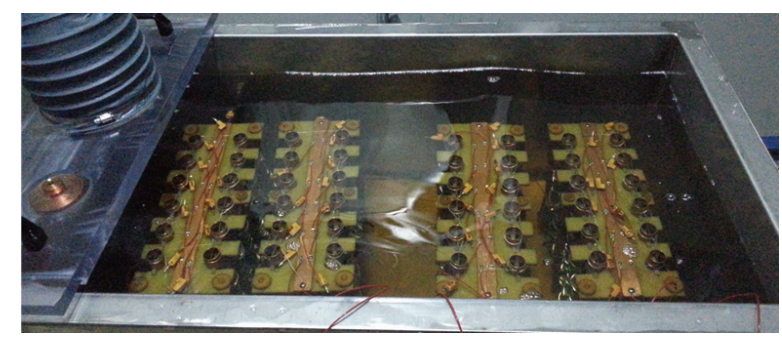

Fig. 3. Chamber with 48 specimens for degradation specimen was properly made.

\subsection{Thermal and electrical degradation method}

The chamber was manufactured in order to apply the thermal and electric stress to the specimens. As shown in Fig. 3, 8-layer and 10-layer insulation model cables were installed in the chamber. All model cables were completely immersed under alkyl-benzene insulation oil and the temperature of oil was controlled for the thermal degradation of the specimens. Aging temperatures for the accelerated thermal degradation were decided as $105^{\circ} \mathrm{C}, 120^{\circ} \mathrm{C}, 135^{\circ} \mathrm{C}$ in considering the range between the maximum permissible temperature of $85^{\circ} \mathrm{C}$ in the oil-filled equipment and the flash point of $142^{\circ} \mathrm{C}$ for the insulation oil.

In this experiment, due to the high pressure at high aging temperature in the quite-big sized chamber, it is not easy to make the chamber with enclosed structure to avoid the air contact. Therefore, the effect of the exposure of air should be considered in the study.

As the electrical degradation, the AC voltage of $13.2 \mathrm{kV}$ was applied to all specimens under each aging temperature. Using two types in insulation thickness, $10.56 \mathrm{kV} / \mathrm{mm}$ $\left(2 \mathrm{E}_{0}\right)$ for 10-layer specimens and $13.2 \mathrm{kV} / \mathrm{mm}\left(2.5 \mathrm{E}_{0}\right)$ for 8-layer specimens were applied in considering the average electric field of $5.29 \mathrm{kV} / \mathrm{mm}\left(\mathrm{E}_{0}\right)$ in $154 \mathrm{kV}$ OF cable.

The aging period was 10 weeks for each aging temperature conditions and at every 2 weeks impulse breakdown stress and tensile strength were measured.

For the experiment as mentioned above, the size of the aging chamber should be big for the aging of the many specimens. Thus, the sealing of the aging chamber was impossible because of the huge amount of insulating oil at high temperature. During the aging, a lot of oil vapor occurred, so that the oil vapor recovery system should be needed, which leads that the air contact to the surface of the oil could not be avoidable and further degradation by oxygen was expected. Generally, it is reported that the air can accelerate the degradation with $2 \sim 4.5$ times $[6,7]$.

\subsection{Tensile strength measurement}

To evaluate degradation characteristics for aged papers, tensile strengths were measured according to the specification, 'KS M ISO 1924-2, Paper and board Determination of tensile properties' [8]. Aged papers were taken out from the specimen and cut into the size of $250 \mathrm{~mm} \times 15 \mathrm{~mm}$, then were dried at $85^{\circ} \mathrm{C}$ in air oven.

Tensile strength is defined as the maximum withstand stress of a material while being stretched or pulled before failing or breaking.

$$
T S=\frac{F_{t}}{b t}
$$

Here, $F_{t}$ : Maximum tensile load [N] 
$b:$ Initial width of specimen [mm]

$t \quad$ : Initial thickness of specimen [mm]

\subsection{High temperature impulse breakdown method}

At the elevated temperature the level of breakdown voltage would be generally decreased. In this study, the same method in the type test for the OF cable was adopted as high temperature impulse breakdown experiments for cable model specimens. Temperature of the specimens in the oil bath was $85^{\circ} \mathrm{C}$, the maximum permissible temperature of the oil-filled equipment.

For all specimens, at first, 10-times each positive and negative $1.2 / 50 \mu$ s standard lighting impulse voltages were applied respectively at the level of the electric field of $750 \mathrm{kV}$ BIL of $154 \mathrm{kV}$ OF cable, that is $44.1 \mathrm{kV}_{\text {imp }}$ for 8layer $\left(1 \mathrm{~mm}\right.$ thickness) specimens and $55.1 \mathrm{kV}_{\text {imp }}$ for 10 layer $(1.25 \mathrm{~mm}$ thickness) specimens. Then, with the step of $4 \mathrm{kV}_{\text {imp }}$, impulse voltages were applied until the breakdown occurred.

\section{Results and Discussions}

\subsection{Lifetime analysis using tensile strength}

Fig. 4 shows the changes of tensile strength with aging time for various aging temperatures, in which tensile strengths were more severely decreased with at higher temperature. The decrease with aging temperatures was followed according to the Eq. (2) [9].

$$
T S(t)=T S_{0} e^{-C_{T S}(T) t}
$$

Here,

$T S(t) \quad$ : Tensile strength at time $t$

$T S_{0} \quad$ : Initial tensile strength

$C_{T S}(T)$ : Aging coefficient according to aging condition supposed to follow the Arrhenius relationship

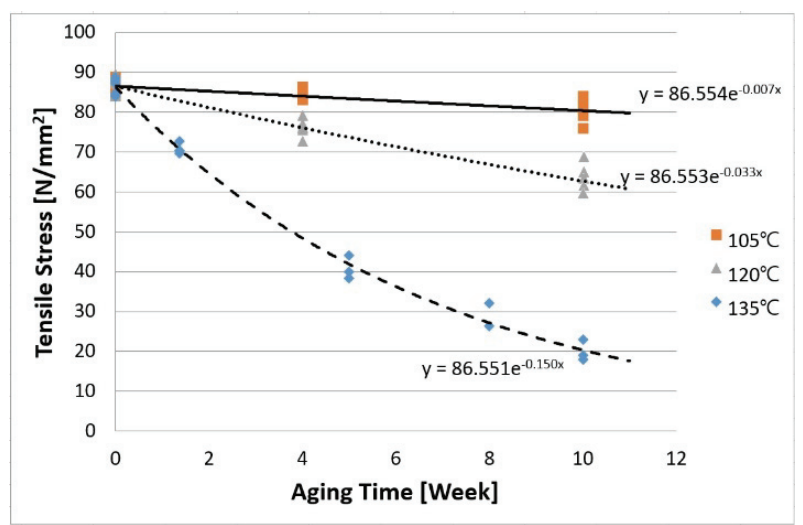

Fig. 4. Changes of tensile strength with aging time for various aging temperatures

$$
C_{T S}(T)=A e^{\frac{E_{a}}{R T}}
$$

$E_{a}:$ Activation energy of Kraft paper (113 [kJ/mol] [9])

$T$ : Absolute temperature $[\mathrm{K}]$

$R$ : Universal constant $(8.314[\mathrm{~J} / \mathrm{mol}])$

$A$ : Environmental factor such as water, oxygen, acid, etc

The lifetime of Oil-Paper insulation was analyzed through the following process using tensile strength data with aging time.

1) Derive trend formula and aging coefficient values $C_{T S}(T)$ with aging temperature according to Eq. (2)

$$
\begin{aligned}
& T S(t)_{105^{\circ} \mathrm{C}}=86.6 e^{-0.0074 t}, \ln \left(T S(t)_{105^{\circ} \mathrm{C}}\right)=0.0074 t+4.4608 \\
& T S(t)_{120^{\circ} \mathrm{C}}=86.6 e^{-0.0330 t}, \ln \left(T S(t)_{120^{\circ} \mathrm{C}}\right)=0.0330 t+4.4608 \\
& T S(t)_{135^{\circ} \mathrm{C}}=86.6 e^{-0.1404 t}, \ln \left(T S(t)_{135^{\circ} \mathrm{C}}\right)=0.1504 t+4.4608
\end{aligned}
$$

2) Calculate Arrhenius relationship coefficient $E_{a} / R T$ and environmental factor $A$ with aging temperature according to Eq. (3)

3) Derive trend formula for environmental factor $A$ as shown in Fig 5

$$
\begin{aligned}
& A=2.05 \times 10^{-49} \cdot e^{0.1885 T} \\
& \ln A=0.1885 \mathrm{~T}-112.11
\end{aligned}
$$

4) Calculate the value $A$ at $85^{\circ} \mathrm{C}$ using Eq. (4) and complete the lifetime formula at $85^{\circ} \mathrm{C}$

$$
\operatorname{TS}(t)_{85^{\circ} \mathrm{C}}=86.6 e^{-0.001279 t}, \ln \left(T S(t)_{85^{\circ} \mathrm{C}}\right)=0.001279 \mathrm{t}+4.4608
$$

This process was based on the Eq. (2) and Eq. (3) under the assumption that the environmental factor $\mathrm{A}$ is constant in reference [9]. However, in this study, the value A was changed with the different aging temperature. It is found out that the factor A followed the exponential function quite well as shown in Fig. 5. This relationship was also

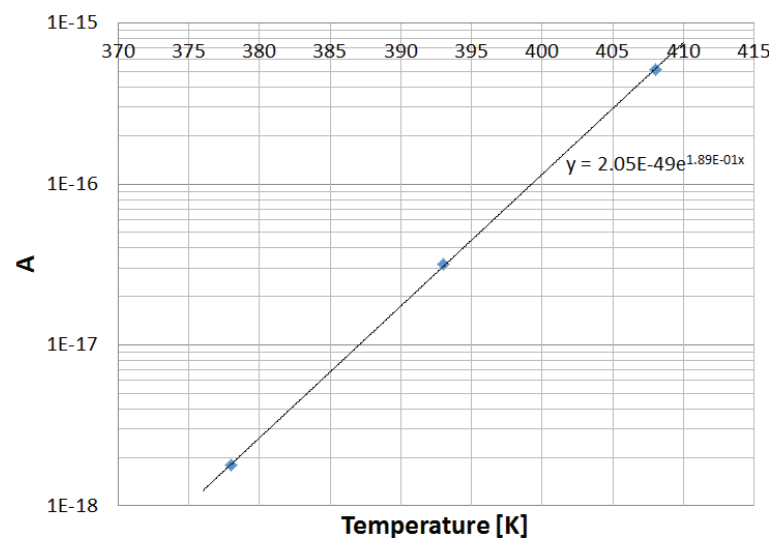

Fig. 5. Derivation of trend formula for $A$ 
Table 1. Result of calculation for lifetimes and accelerated aging factors

\begin{tabular}{c|c|c|c|c|c}
\hline$T\left[{ }^{\circ} \mathrm{C}\right]$ & $E_{a} / R T$ & $C_{T S}(T)$ & $A$ & $\begin{array}{c}\text { Lifetime in } \\
\text { equivalent } \\
\text { operating years } \\
\text { (weeks)/(yrs) }\end{array}$ & $\begin{array}{c}\text { Accelerated } \\
\text { aging } \\
\text { factor }\end{array}$ \\
\hline 135 & $2.93 \mathrm{E} 14$ & 0.1504 & $5.13 \mathrm{E}-16$ & $4.6 / 0.1$ & 117.6 \\
\hline 120 & $1.05 \mathrm{E} 15$ & 0.0330 & $3.15 \mathrm{E}-17$ & $21.0 / 0.4$ & 25.8 \\
\hline 105 & $4.13 \mathrm{E} 15$ & 0.0074 & $1.79 \mathrm{E}-18$ & $93.7 / 1.8$ & 5.8 \\
\hline 85 & $3.08 \mathrm{E} 16$ & 0.00128 & $4.16 \mathrm{E}-20$ & $542.0 / 10.4$ & 1.0 \\
\hline
\end{tabular}

reported in the authors' paper [10] for the lifetime assessment of flexible cable.

Concerned with the lifetime limit, $50 \%$ value in tensile strength compared with the initial value [5] was adopted and the lifetime in equivalent operating years was calculated at different temperatures. Table 1 shows lifetimes and accelerated aging factors at various aging temperatures.

The lifetime at $85^{\circ} \mathrm{C}$ was calculated with 10.4 years, which is shorter than that reported in other papers such as 31.35 years calculated with decreased DP (Degree of Polymerization) value of 300 from the initial one of 1,000 when the oil-filled cable operates continuously at $85^{\circ} \mathrm{C}$ [2] and the designed lifetime of about 30 years with operation at $85^{\circ} \mathrm{C}$ in considering decreased DP value of 300 [4]. The reason of 3 times faster aging in this study compared with these values would be due to the exposure to air during the aging. In this study, the chamber could not be made with airtight structure because of the experiment for many model cables concurrently and air was blown due to the ventilation of a lot of oil vapor generated at high aging temperature. So, air contact of oil was avoidable, which resulted in rapid degradation of insulation papers. As mentioned above, it is reported that the air can accelerate the degradation with 2 4.5 times [6,7], so the analysis in this study seems to be reasonable.

\subsection{Analysis for impulse breakdown voltages at high temperature}

Fig. 6 shows the impulse breakdown electric fields at high temperature according to aging temperatures and aging time. Impulse BD strength was decreased with the temperature and showed the trend of slight decrease with time. Impulse BD strengths in case of 8-layer $(1 \mathrm{~mm}$ thickness) specimen which had aged with $2.5 E_{0} \mathrm{AC}$ electrical stress were higher than those in case of 10-layer $\left(1.25 \mathrm{~mm}\right.$ thickness) specimen with $2.0 E_{0} \mathrm{AC}$ electrical stress. This result can be analyzed with thickness effect as shown in Fig. 7 where impulse BD strength was decreased with $(-0.26)$ power, which was smaller value compared with usual value of (-0.5). In case of impulse BD strength of new insulation papers $(0.101 \mathrm{~mm}$ thickness per a paper, sphere-to-sphere electrode structure, in oil, room temperature), the power in thickness effect was calculated about $(-0.5)$ as shown in Fig. 8, which is usual.

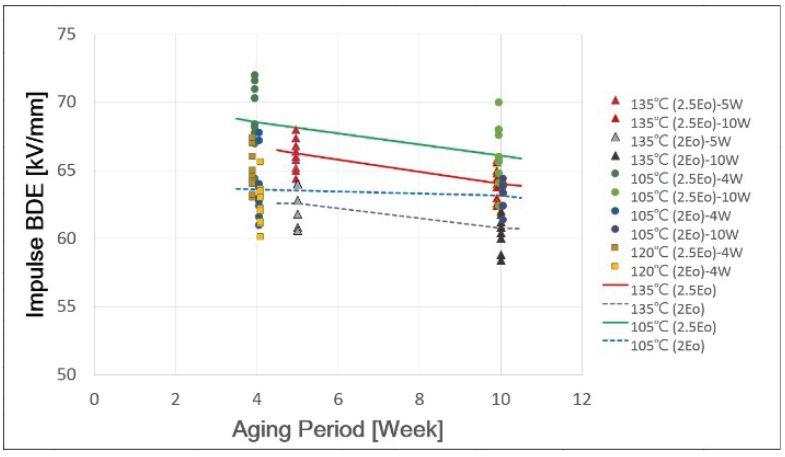

Fig. 6. Impulse BD strength at high temperature according to aging temperatures.

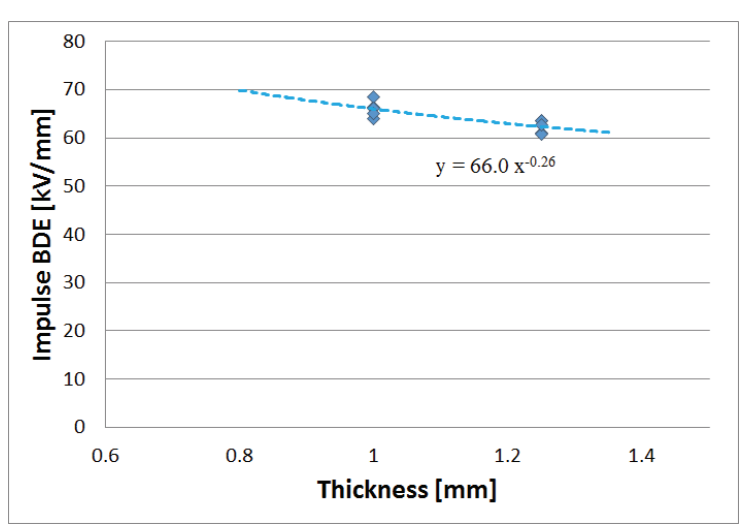

Fig. 7. Thickness effect in impulse BD strength for aged specimens $\left(135^{\circ} \mathrm{C}, 10\right.$ weeks)

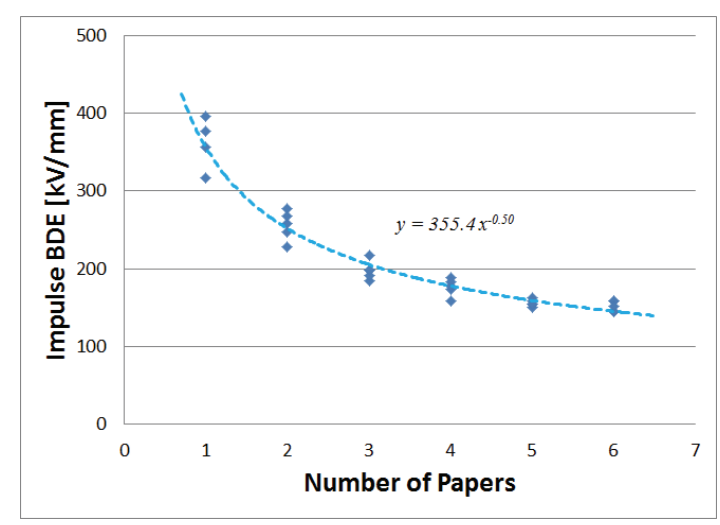

Fig. 8. Thickness effect in impulse BD strength for new insulation paper layers

It means that (-0.26) power in Fig. 7 would be the result of not only thickness effect but also electrical aging of higher AC field $\left(2.5 E_{0}\right)$.

\subsection{Analysis for impulse BD strength considered with equivalent operating years}

Impulse BD strengths for cable model specimens as shown in Fig. 6 were just described with their measured 


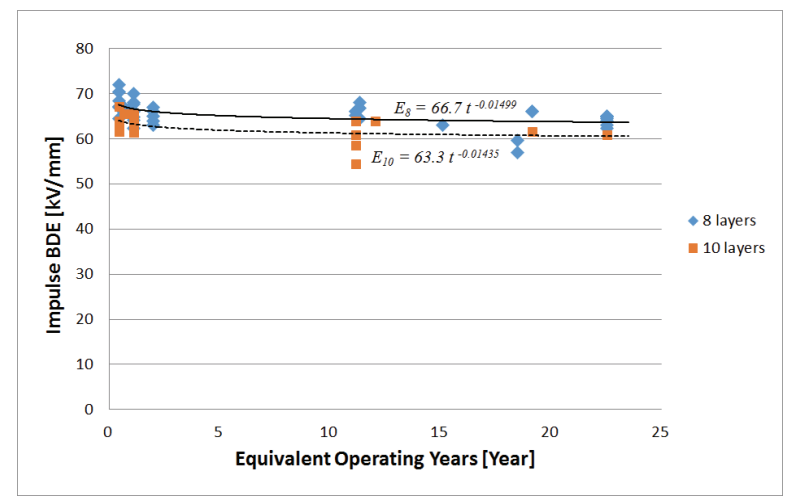

Fig. 9. Impulse $\mathrm{BD}$ strengths with equivalent operating years

values according to aging temperatures and aging time. In this section, they were reanalyzed using equivalent operating years which were deduced from the analysis of tensile strength for aged papers as shown in Table 1.

Fig. 9 shows the impulse BD strengths with equivalent operating years in considering accelerated aging factors for each aging temperature. The results were followed with the inverse power law as shown in Eq. (7).

$$
E^{n} t=C, \quad \text { that is, } \quad E=C t^{-n}
$$

Here, $E$ : BD strength $[\mathrm{kV} / \mathrm{mm}]$

$$
\begin{array}{ll}
t & : \text { Operation time } \\
n & : \text { Lifetime index } \\
C & : \text { Constant }
\end{array}
$$

Even though Eq. (7) is generally used as the V-t characteristics for long-term breakdown under the $\mathrm{AC}$ voltage application, it is possible for this equation to be adopted in this study because after the AC stresses with $2.0 E_{0}$ (10 layers) and $2.5 E_{0}$ (8 layers) were long-termly applied to model cables then impulse breakdown were carried out as the evaluation method. Formulas of inverse power law for $2.0 E_{0}$ (10 layers) and $2.5 E_{0}$ (8 layers) can be described as follows.

8-layer (1mm thickness, $\left.2.5 E_{0}\right)$ model cables :

$$
E(t)=66.7 t^{-0.01499}, \quad n=66.7
$$

10-layer (1mm thickness, $\left.2.0 E_{0}\right)$ model cables :

$$
E(t)=63.3 t^{-0.01435}, \quad n=69.7
$$

The lifetime index for 8-layer specimen was a little smaller than that for 10-layer specimen, which seems to be due to higher electrical stress of $2.5 E_{0}$ during the long-term AC electrical aging. These indices are similar to the reported value of 68 for AC long-term breakdown in model cables rather than the value of transformer insulation models [3], which would be reasonable because the cable model specimen was adopted in this study. The values of theses indices are so large that the electrical degradation

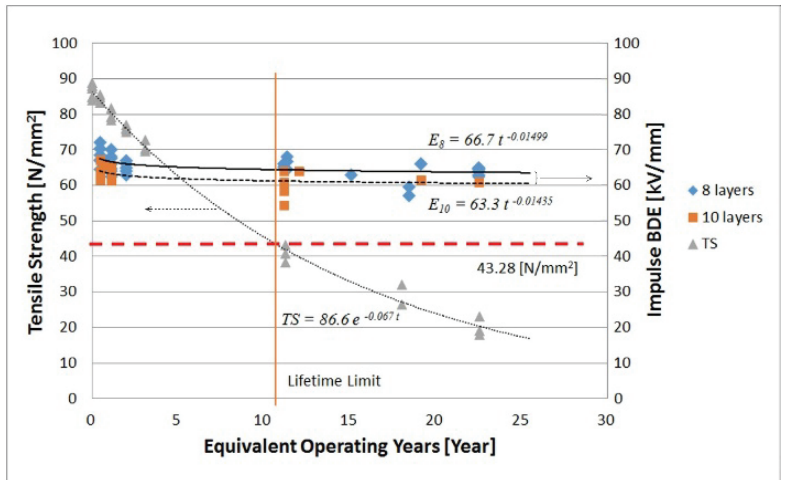

Fig. 10. Tensile strengths and impulse BD strengths with equivalent operating years

might not be meaningful on the lifetime of the oil-paper insulation.

In Fig. 10, tensile strength results for different aging temperatures with the equivalent operating years were added on the Fig 9. As described above, the lifetime limit (50\% decrease in TS) was 10.4 equivalent operating years, whereas impulse BD strengths showed just about 3\% decrease (8-layer : from $66.7[\mathrm{kV} / \mathrm{mm}]$ to $64.4[\mathrm{kV} / \mathrm{mm}]$, 10-layer : from $63.3[\mathrm{kV} / \mathrm{mm}]$ to $61.2[\mathrm{kV} / \mathrm{mm}])$ at the lifetime limit in the mechanical property of insulation paper. It means that electrical degradation does not severely affect to the lifetime of the oil-paper insulation whereas thermal degradation can be the major factor.

\section{Conclusion}

In this study, throughout the analysis on tensile strength and impulse breakdown for oil-paper insulation specimens which had multiple-degraded with thermal and electrical stresses, the follows are remarked.

Tensile strengths were exponentially decreased with aging time and aging temperature. From the deduced formula, the lifetime at $85^{\circ} \mathrm{C}$ was calculated with 10.4 equivalent operating years due to exposure to air during the experiment, which is one third value compared with designed oil-paper insulation lifetime.

Impulse breakdown strengths at high temperature were slightly decreased with aging time and aging temperature. Higher electric field showed a minor effect on the degradation.

Lifetime indices were deduced to be 66.7 (1 $\mathrm{mm}$ thickness, $\left.2.5 E_{0}\right)$ and 69.7 (1.25 mm thickness, 2.0 $\left.E_{0}\right)$ using the relationship between impulse BD strength and equivalent operating years. Compared with the lifetime limit in the mechanical property (tensile strength) of insulation paper, impulse BD strengths showed just a slight decrease. Therefore, it can be deduced that electrical degradation does not give an important role to the lifetime of oil-paper insulation whereas thermal degradation can be the major factor. 


\section{References}

[1] Lukasz Chmura et al, "Use of Dissipation Factor for Life Consumption Assessment and Future Life Modeling of oil-Filled High-Voltage Power Cables," IEEE Electrical Insulation Magazine, vol. 28, no. 1, pp. 27-37, 2012,

[2] Lukasz Chmura et al, "Life cures for new and thermally aged oil-impregnated paper insulation," 2013 Electrical Insulation Conference, pp. 45-48, Ottawa, Ontario, Canada, 2-5 June, 2013

[3] A. M. Emsley and G. C. Stevens, "Review of Chemical Indicators of Degradation of Cellulosic Electrical Paper Insulation in Oil-Filled transformers," IEE Proc.-Sci. Meas. Technol., vol. 141, no. 5, pp. 324-334, September 1994.

[4] Yukiuasu Shirasaka et al, "Cross-sectional comparison of Insulation Degradation mechanisms and Lifetime Evaluation of Power Transmission Equipment," IEEE Transactions on Dielectrics and Electrical Insulation, vol. 16, no. 2, pp. 560-573, April 2009.

[5] IEC 60076-7, "Loading guide for oil-immersed power transformers," 2009.

[6] A.M. Emsley, "Degradation of cellulosic insulation in power transformers. Part 3: Effects of oxygen and water on ageing in oil," IEE Proc-Sci Meas. Technol. vol. 147, no. 3, pp. 115-119, November 2000.

[7] Nick Lelkakis, "Ageing Rate of paper insulation used in power transformers, Part 1: Oil/paper system with Low Oxygen concentration," IEEE Transactions on Dielectrics and Electrical insulation, vol. 19, no. 16, pp. 1999-2008, December 2012.

[8] KS M ISO 1924-2, Paper and board - Determination of tensile properties.

[9] H. P. Gasser, "Determining the aging parameters of cellulosic insulation in a transformer," IEE, High Voltage Engineering Symposium, no. 467, 4.143147.P1, 22-27 August 1999.

[10] Jeongtae Kim, Ji-Sub Yoon and Sang-Won Choi, "Lifetime Assessment Method using Multiple-Stress Acceleration Aging for Flexible Cable of Portable Electric Machines," Journal of Electrical Engineering Technology, vol. 11, No. 5, pp. 1377-1382, 2016.

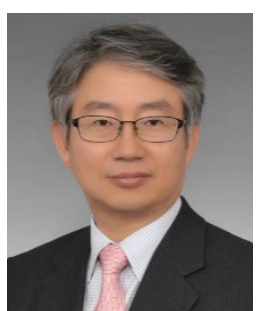

Jeongtae Kim $\mathrm{He}$ received B.S degree(1982), M.S degree(1987) and Ph.D(1992) in electrical engineering from Hanyang University. He was a visiting professor of Mississippi State University from 2007 2008. Also, he was a Regular Member of CIGRE SCB1 (Insulated Cables) from 2000 2008. His main research fields are electrical insulation design and diagnosis for various electric equipment, especially partial discharge diagnostic technology.

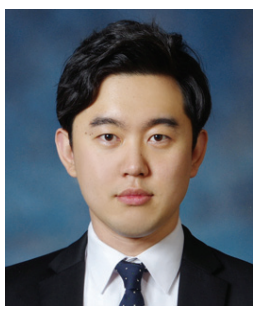

Woobin Kim He received B.S and M.S degrees in electrical engineering from Daejin University, Pocheon Korea in 2014 and 2016, respectively. Currently, $\mathrm{He}$ is working for Sanil Electric Co., Ltd. Institute of technology, Ansan-si, Korea. His research interests include aging mechanisms, lifetime assessment and partial discharge diagnostic technology.

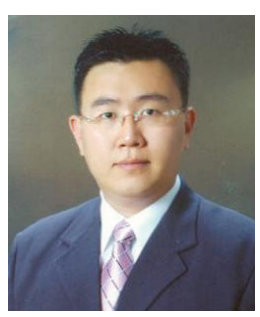

Hung-Sok Park He received his B.S, M.S and Ph.D. degree in Electrical Engineering from Chungnam National University, Daejeon, Korea in 2003, 2005 and 2011 respectively. He has been working at the KEPCO Research Institute from 2004 where he is currently a researcher at Power Transmission Laboratory. He is mainly interested in certification test and analysis of power cable system.

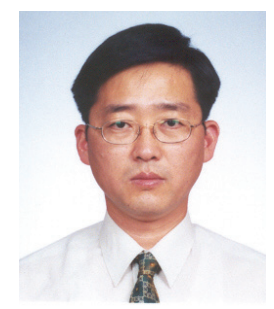

Ji-Won Kang He received his B.S., M.S. and Ph.D. degree in Electrical Engineering from Hanyang University, Seoul, Korea in 1987, 1993 and 2003 respectively. He has been worked for Korea Electric Power Research Institute since 1992. He is currently a Chief researcher in the Power Transmission Laborotory. His current research interests are power systems operation, analysis and diagnosis of power cable systems. 